\title{
On a Method of Determining Friction Velocity in a Wind-wave Tunnel
}

\author{
by \\ Tatsuo Konishi and Takeshi Uji \\ Meteorological Research Institute, Tokyo
}

(Received September 4, 1978)

\begin{abstract}
A method of determining friction velocity $u_{*}$ by measurement in a wind-wave tunnel is proposed, based on the similarity law of the turbulent boundary layer. The method is based essentially on the application of a two-layer model to the velocity defect profile; a logarithmic velocity distribution is applied to the inner boundary layer and Hama's profile, $F=9.6(1-\eta)^{2}$, to the outer layer, where $F$ is the non-dimensional velocity defect function, $\eta$ the non-dimensional height.

This method can determine friction velocity $u_{*}$ within a few percent of uncertainty, and has higher accuracy than the logarithmic method generally used, in some case of wind-wave tunnel experiments. The method works with precision if used in the early stage of development of the turbulent boundary layer, but not if used in the later stage, when the turbulent boundary layer has fully developed and the whole air flow in the wind-wave tunnel becomes turbulent.
\end{abstract}

\section{Introduction}

One of the most important problems in the air-sea interaction processes is to determine the shear stress acting on the water surface. To parameterize the stress, many empirical formulas have been presented, expressing the drag coefficient by means of wind velocity and stability conditions. Recently, friction velocity, which we introduce as $\sqrt{\tau_{0} / \rho}$ where $\tau_{0}$ is the shear stress on the water surface and $\rho$ is air density, this definition of $u_{*}$ being followed through out this paper, becomes more essential parameter associated with the progress of wind-wave generation theory. It has been established by many authors that the spectral forms and some non-dimensional macroscopic physical quantities of wind-waves are controlled by rules of similarity (Toba, 1973; Mitsuyasu et al., 1973 and Kawai et al., 1977), and $u_{*}$ is used in their similarity formulas as a scale.

The shear stress or friction velocity has also physical importance in the air-sea boundary processes. The Wind-waves Studying Group of Tohoku University (Toba et al., 1975 ; Okuda et al., 1977) showed that forced convections accompanying wind-waves were originated in the large shear stress just before the crest. Uji (1978) showed analytically that neglecting the shear stress in the theory of wind-wave generation was not reasonable even if developed wind-waves seemed to be irrotational.

All theories and experiments mentioned above suggest that friction velocity is one of the very important parameters when describing the mechanism of wind-wave generation.

Several methods have been known to determine friction velocity as reviewed by Toba (1970), but the following two are used popularly in experiments in the wind-wave tunnel. The first one is the so-called "eddy 
correlation method", in which the Reynolds stress is measured directly with a hot-wire or a hot-film anemometer. This is the best one from the theoretical standpoint, but difficulties of dynamic calibration and accurate orientation of the apparatus prevent this method from coming into general use. In addition, a hot-wire or a hot-film anemometer is so expensive and also not adequate for operation near the water surface. The second is the "logarithmic profile method", which determines friction velocity from the vertical logarithmic gradient of wind profile. This is used commonly by many researchers because of its simplicity. But it will be shown below that the error due to the uncertainty of the region where the logarithmic profile should be applied is not small and reaches fifty percent in some cases, when we use the method over the water surface to acquire $u_{*}$. Especially when the profile seems to be distorted by waves or when logarithmic boundary layer has not developed fully, the logarithmic profile method leads to large errors in obtaining $u_{*}$; for example, in the case of Fig. 1, $u_{*}$ and $z_{0}$ by logarithmic profile method vary from $15.5 \mathrm{~cm} / \mathrm{sec}$ to $61.6 \mathrm{~cm} / \mathrm{sec}$ and from $2.09 \times 10^{-8} \mathrm{~cm}$ to $2.04 \times 10^{-2} \mathrm{~cm}$ respectively corresponding to the selection of 3 points or 13 points from the lowest measuring point.

Takeda (1963) and Nan-niti (1968) found in their field experiments that a vertical profile of wind on the sea has sometimes a

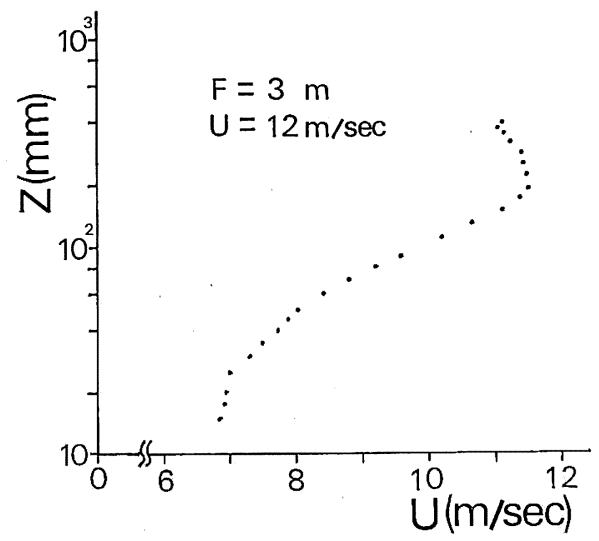

Fig. 1. Example of velocity profile over water waves. Inlet velocity is $12 \mathrm{~m} / \mathrm{sec}$ and measuring point is at fetch $3 \mathrm{~m}$. kink. Plate and Hidy (1967), Kato and Sano (1971), Chang Plate and Hidy (1971) and Suzuki (1978) found the same phenomena in experiments in the wind-wave tunnel. Such wind profiles can be separated into three parts to which different logarithmic profile could be applied, and there is no clear physical reason to determine the region where the logarithmic profile method must be referred to. Kato and Sano (1971) stated that the Reynolds stress obtained by the eddy correlation method was experimentally equal to that obtained by applying the logarithmic profile method to the lowest portion of the logarithmic profile with scarce data. Suzuki (1978) said, on the other hand, that the empirical relation which was given by $u_{*}$ and $z_{0}$ obtained by applying the logarithmic profile method to the middle portion of log-profile agreed reasonably well with Charnock's and Kunishi's relation (Charnock, 1955 and Kunishi, 1963).

The purpose of this paper is to propose a new method to determine friction velocity using the whole wind profile in a wind-wave tunnel, including log-profile, but this method will be used exactly before the boundary layer has developed fully to fill up the windwave tunnel.

\section{Fundamental concept of the proposed method}

The method presented for determining $u_{*}$ is based on the similarlity of the turbulent boundary layer, in which the velocity profiles and stress profiles at different values of fetches, normalized by the scales of length and velocity at each point, all have the same shape. As mentioned below, this idea can be applied reasonably well to the boundary layer over wind-waves in a wind-wave tunnel, rather than to that over a flat plate.

According to dimensional analysis, a velocity profile in a turbulent boundary layer may be expressed by the so-called "velocity defect profile" such as

$$
u_{\infty}(x)-\bar{u}(x, z)=u_{*}(x) \cdot F(\eta, \omega),
$$


where $x$ is the fetch length, $z$ the height from the boundary, $u_{\infty}(x)$ the external veloc. ity, $\bar{u}(x, z)$ the mean horizontal wind velocity, $u_{*}(x)$ the friction velocity and $F(\eta, \omega)$ the non-dimensional profile function. Where $u_{*}=$ $\left.\tau_{0} / \rho\right)^{1 / 2}, \eta=z / \delta, \omega=u_{*} / u_{\infty}$ and $\tau_{0}$ means the shear stress on the boundary and $\delta$ is the height at which $\bar{u}(\delta)$ is 99 percent of $u_{\infty}(x)$. If $\eta \rightarrow 0$, Eq. (2.1) may tend to the logarithmic velocity distribution; consequently the relation

$$
\frac{1}{\omega} \sim \frac{1}{\kappa} \ln \frac{\delta}{k_{r}},
$$

is required, where $\kappa$ is von Karman's constant and $k_{r}$ the roughness length.

Eq. (2.1) must satisfy the equations of motion and continuity,

$$
\begin{aligned}
& \bar{u} \frac{\partial \bar{u}}{\partial x}+\bar{w} \frac{\partial \bar{u}}{\partial z}=-\frac{1}{\rho} \frac{\partial \bar{p}_{\infty}}{\partial x}+\frac{1}{\rho} \frac{\partial \tau}{\partial z}, \\
& \frac{\partial \bar{u}}{\partial x}+\frac{\partial \bar{w}}{\partial z}=0
\end{aligned}
$$

where $\tau=-\rho \overline{u^{\prime} w^{\prime}}+\mu d \bar{u} / d z, \tilde{p}_{\infty}$ is the external pressure gradient and $\bar{w}$ the mean vertical velocity. Here we assumed that the flow is incompressible, stationary and two dimensional, the vertical gradients of dependent variables are much greater than the horizontal one and $\overline{u^{\prime 2}}$ is less than $\bar{u}^{2}$. Now we will introduce a non-dimensional function, $g(\eta, \omega)$, as follows:

$$
\tau=\rho u_{*}^{2} g(\eta, \omega) .
$$

Substituting Eqs. (2.1) and (2.4) in Eq. (2.3), we obtain

$$
\begin{aligned}
& \omega \Pi\left(2 F-\omega F^{2}\right) \\
& +\left(\frac{1}{\omega}-\frac{d \delta}{d x}-\omega \Pi\right)\left(\eta-\omega \int_{\eta_{0}}^{\eta} F d \eta\right) \frac{d F}{d \eta} \\
& +\omega \Pi \frac{d F}{d \eta} \eta_{0}-\frac{\eta_{0}}{\omega} \frac{d \delta}{d x} \frac{d F}{d \eta}=\frac{d g}{d \eta},
\end{aligned}
$$

where $\Pi=\left(\delta / \rho u_{*}{ }^{2}\right) d \bar{p}_{\infty} / d x, \eta_{0}=k_{r} / \delta$ and the small variation of $\omega$ with fetch is neglected. The condition for the existence of the similarity of turbulent boundary layer means that Eq. (2.5) is independent of $x$. The suf- ficient conditions for it are

$$
\begin{aligned}
& \Pi=\text { constant }, \\
& \omega=\text { constant },
\end{aligned}
$$

and

$$
\frac{d \delta}{d x}=\text { constant } .
$$

Considering Eq. (2.2), $\eta_{0}$ is also constant and $\delta$ and $k_{r}$ must be proportional to fetch, $x$.

Now, we will clarify that this similaritylaw of the turbulent boundary layer is more applicable to the boundary layer over windwaves rather than to that over a flat plate. In order to see whether the third equation of Eqs. (2.6) is satisfied in a wind-wave tunnel or not, Fig. 2 shows the variation of wind velocity profiles with the fetch measured in the wind-wave tunnel of the Meteorological Research Institute. In this figure, the abscissa is the logarithmic height from the mean water level, the ordinate is the mean wind velocity, and r.p.m. means revolutions of the motor per minute. 300 r.p.m. and 600 r. p. m. correspond to winds of $4.13 \mathrm{~m} / \mathrm{sec}$ and $8.70 \mathrm{~m} / \mathrm{sec}$ at the inlet respectively. The arrows in the figure which indicate the edges of the boundary layer, show that $\delta$ is about $20 \mathrm{~mm}$ at $x=1 \mathrm{~m}$ and about $40 \mathrm{~mm}$ at $x=2 \mathrm{~m}$

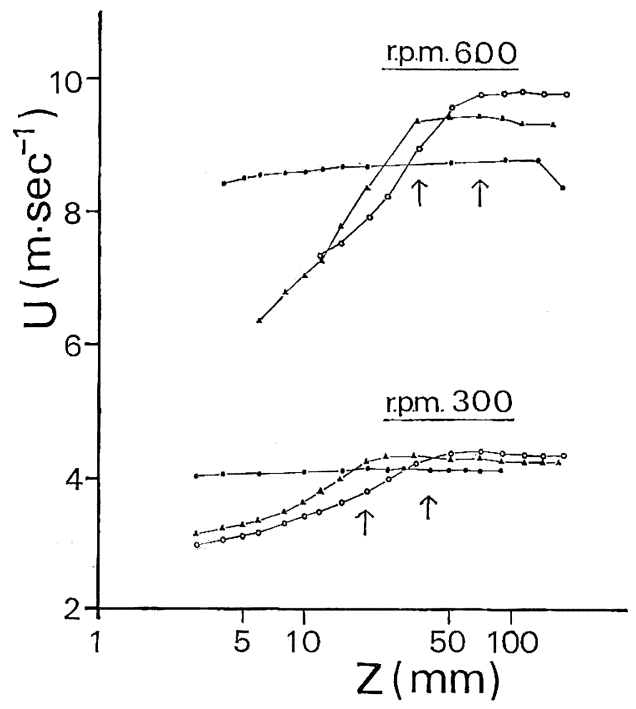

Fig. 2. Variation of velocity profile with fetch, - $=0 \mathrm{~m}, \mathbf{A}=1 \mathrm{~m}, \bigcirc=2 \mathrm{~m}$. The arrows indicate the edges of boundary layer. 
for 300 r.p. m. and about $35 \mathrm{~mm}$ at $x=1 \mathrm{~m}$ and $70 \mathrm{~mm}$ at $x=2 \mathrm{~m}$ for $600 \mathrm{r} . \mathrm{p} . \mathrm{m}$. These results show that $\delta$ is proportional to fetch $x$. Also we may see the same results in Figs. 14 and 16 of Kato and Takemura (1966). The condition which $k_{r}$ should satisfy cannot be determined from these measurements because we can not determine it without serious error due to the insufficient depth of the logarithmic layer as seen in Fig. 2, but it may be reasonable to suppose $k_{r}$ to be proportional to $x$, rather than to be constant through the fetch in the boundary layer over wind-waves developing with fetch. Values of $\omega$ obtained from measurements at short fetch in the wind-wave tunnel at the Meteorological Research Institute and Tohoku University are nearly equal and constant, i.e. 0.04. Strictly speaking, direct measurements of Reynolds stress are necessary for justifying the introduced conditions of $\omega$ and $\Pi$. But it may be expected from the consideration above that the similarity of the turbulent boundary layer exists over wind-waves developing with fetch, rather than over a flat plate.

\section{Non-dimensional profile function, $F(\eta)$}

In order to determine friction velocity using Eq. (2.1), we need to know the nondimensional profile function, $F(\eta)$. As the starting point, we take Eq. (2.5).

Assuming the variation of external velocity with fetch to be $u_{\infty}(x)-u_{\infty}\left(x_{0}\right) \sim\left(x-x_{0}\right)^{m}$ and using Bernoulli's equation, the relation between the non-dimensional pressure gradient and $m$, is given by

$$
\Pi=-\frac{m}{\omega^{2}} \frac{d \delta}{d x} .
$$

Provided that $\omega \sim 10^{-2}, m \sim 10^{-1}$ or $10^{-2}, d \delta /$ $d x \sim 10^{-2}$ or $10^{-3}, F \sim 1$ and $\eta \sim 1$, Eq. (2.5) can be reduced to

$$
\frac{1}{\omega} \frac{d \delta}{d x}\left(-2 m F+(m+1) \frac{d F}{d \eta}\right)=\frac{d g}{d \eta},
$$

approximately, using Eq. (3.1).

We assume that the eddy viscosity is constant over $\eta \geqq 0.15$ following Clauser (1954) and Townsend (1976), and the right-hand side of Eq. (3.2) has the form of

$$
\frac{d g}{d \eta}=-\frac{1}{R_{s}} \frac{d^{2} F}{d \eta^{2}},
$$

where $R_{s}=u_{*} \delta / \nu_{e}$, and $\nu_{e}$ is the eddy viscosity. Finally we have

$$
\frac{d^{2} F}{d \eta^{2}}+R^{2} \frac{d F}{d \eta}-R^{2} n F=0
$$

where $R^{2}=\frac{m+1}{\omega} R_{s} \frac{d \delta}{d x}$ and $n=\frac{2 m}{m+1}$.

general solution of Eq. (3.4) is given by

$$
\begin{aligned}
F= & C \sum_{k=0}^{\infty} \frac{n(n-2) \cdots(n-2 k)}{(2 k) !}(R \eta)^{2 k} \\
& +C^{\prime} \sum_{k=0}^{\infty} \frac{(n-1)(n-3) \cdots(n-2 k-1)}{(2 k+1) !} \\
& (R \eta)^{2 k+1} .
\end{aligned}
$$

Especially, in the case of $n=0$ (equivalent to $m=0)$ and $n=1(m=1)$, the solutions are

$$
\begin{aligned}
& F(\eta)_{n=0}=C_{1}+C_{2} \int_{0}^{R \eta} e^{-t^{2} / 2} d t, \\
& F(\eta)_{n=1}=C_{3}+C_{4} \cdot R \eta \int_{0.15 R}^{R \eta} \frac{e^{-t^{2} / 2}}{t^{2}} d t .
\end{aligned}
$$

Assuming the boundary conditions that wind velocity in the boundary layer is connected to external velocity at $\eta=1$ and smoothly shifted to the log-profile in the lower layer at $\eta=0.15$, the integral constants $C_{1}, C_{2}, C_{3}$ and $C_{4}$ are determined consequently, and a

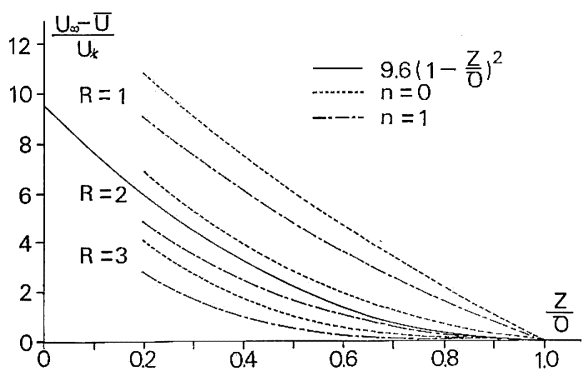

Fig. 3. Computational velocity defect profile with variation of the magnitude of pressure gradient. Parameters should be refered to the text. 
family of velocity profiles is obtained with two parameters $(R, n)$. For instance, the solutions, when $R=1,2$ and 3 and $n=0$ and $n=1$, are shown in Fig. 3.

Monin and Yaglom (1971) show that Hama's equation,

$$
F(\eta)=9.6(1-\eta)^{2},
$$

approximates very well many experimental results obtained by different authors, of vertical wind profile in an outer boundary layer, $0.15 \leqq \eta \leqq 1$, over the flat plate, when the pressure gradient is zero. Therefore, when $n=0$, the velocity profile is independent of $R$. Namely $R$ may be constant whether $d \bar{p}_{\infty} / d x$ $=0$ or not, because the variation of $R$ with $m$ is negligibly small; for example the increment of external velocity in our wind-wave tunnel is at best 0.1. Hama's curve corresponds to $R=2.2$ and then calculated curves for $n=0$ and $n=1$ are displayed in Fig. 4 . The profiles of wind velocity in a turbulent boundary layer which contains the usual acceleration of external velocity are mostly between these two curves. Increment of velocity, $m=0.1$, corresponds to $n=1 / 6$ or $n=1 / 5$ and the profiles can be approximated by Hama's equation with an uncertainty about $1 / 6$ or $1 / 5$ of the width of two curves in Fig. 3. It causes errors of at most six or seven percent in determining $u_{*}$.

After all, we may use Hama's equation as an outer profile without large error whether the pressure gradient is zero or not.

Remaining problems for jusifying the application of Hama's equation to the boundary layer over water waves is the effect of water

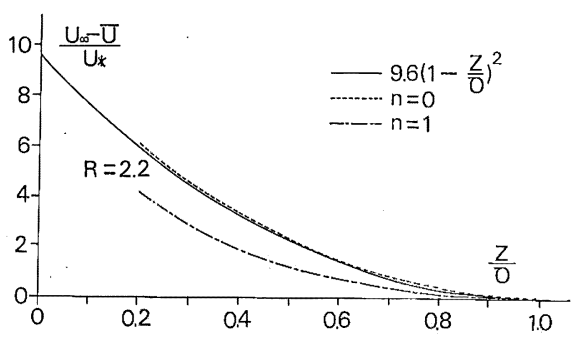

Fig. 4. Computational velocity defect profile which is the best fit of Hama's eq. for zero pressure gradient and $R=2.2$. waves on the profile. According to Chang et al. (1971), the deformation of streamlines of air particles by waves is limited within the wave height as measured from the mean water level, therefore if about 20 percent of boundary layer depth is greater than this height, we may use Hama's equation. Considering the ordinary dimensions of a windwave tunnel, before the condition occurs, the boundary layer assumptions break and the flow changes to the regime of the pipe or channel flow. And so it is natural to think that water waves do not affect Hama's equation in our regime.

For the profile of the inner boundary layer, we may assume a logarithmic velocity defect profile which is connected to Hama's equation with the conditions of continuity of $F(\eta)$ and the derivative of $F(\eta)$ at $\eta=0.15$. This leads to

$$
F(\eta)=-2.448 \ln \eta+2.292,
$$

for $\eta \leqq 0.15$.

A practical process of determining friction velocity is as follows. First, we set $z_{i}, \vec{u}\left(z_{i}\right)$ and initial estimate of $\delta$ as data, then the first order estimate of $u_{*}$ is determined by minimizing the square error between the above mentioned profile function and data. As the next step, using this estimated value of $u_{*}$, the second order estimate of $\delta$ is determined by minimizing the square error. This is repeated until $\delta$ is converged within the given accuracy, of $3 \mathrm{~mm}$.

Thus we can determine the values of friction velocity and boundary layer thickness.

\section{Experimental results and discussion}

We analyze the velocity profiles obtained from the measurements in the wind-wave tunnel at the Meteorological Research Institute (abbreviated M. R. I.). Details of the tunnel are described by Uji et al. (1979). The measuring points are located at distances of $1 \mathrm{~m}$ and $2 \mathrm{~m}$ from the inlet, the measuring conditions are 300 r. p. m. and 600 r. p. m., and the test section of this tunnel is $20 \mathrm{~cm}$ wide and $25 \mathrm{~cm}$ high. In order to see the applica- 
bility of this method at large fetch, we also use the data taken from measurements in the large wind-wave tunnel in Tohoku University (T.U.). The measuring points are located at distances of $3 \mathrm{~m}, 6 \mathrm{~m}, 9 \mathrm{~m}$ and $12 \mathrm{~m}$. The external velocities used in the experiments are about 4,8 and $12 \mathrm{~m} / \mathrm{sec}$ at fetch 3,6 and $12 \mathrm{~m}$ and $2,4,6,8,10,12,14$ and $16 \mathrm{~m} / \mathrm{sec}$ at fetch $9 \mathrm{~m}$. Significant wave height at fetch $3 \mathrm{~m}$ is $0.019,0.543$ and $1.46 \mathrm{~cm}$ at 4,8 and $12 \mathrm{~m} / \mathrm{sec}$ respectively and at fetch $9 \mathrm{~m}$ they are $0.507,1.38,2.49,3.35,4.62,5.86$ and 6.05 $\mathrm{cm}$ corresponding to each external wind speed from 4 to $16 \mathrm{~m} / \mathrm{sec}$. We don't have the waverecord of fetch $6 \mathrm{~m}$ and $12 \mathrm{~m}$. The test $\mathrm{sec}-$ tion of this tunnel is $60 \mathrm{~cm}$ wide and $50 \mathrm{~cm}$ high.

Figs. 5 and 6 show the non-dimensional defect velocity calculated by use of $u_{*}$ and $\delta$ which are determined by the present method. Fig. 5 is based mostly on the data of M.R. I.,

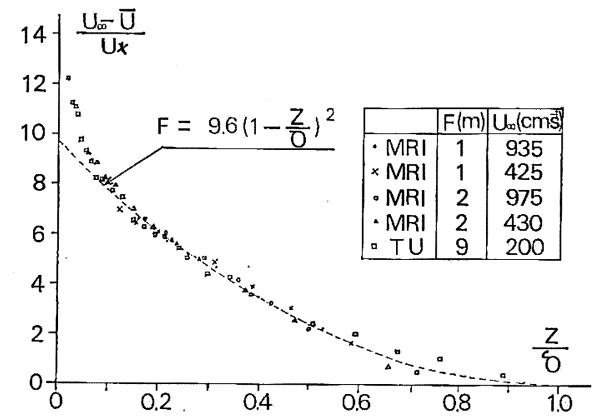

Fig. 5. Velocity defect profile with $u_{*}$ and $\delta$ by the present method. MRI and TU indicate the data obtained from the measurements of the Meteorological Research Institute and Tohoku University respectively.

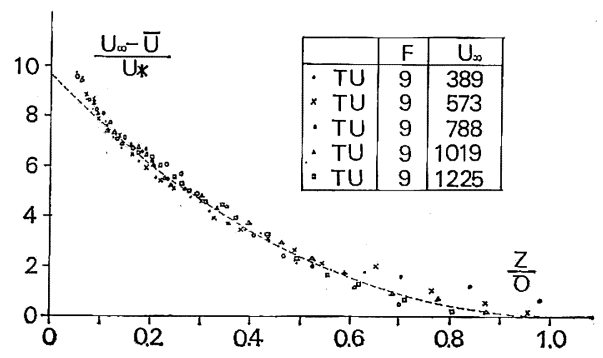

Fig. 6. Velocity defect profile, obtained from the measurements of Tohoku University. and Fig. 6 on that of T. U. The profiles of 21 runs analyzed here have similar scatters in comparison with Hama's profile, but only 10 runs are shown in these figures. It will be concluded from these figures that the feature is very similar in the wind-wave tunnels with different dimensions, but it may be remained whether this method attains the reasonable boundary layer thickness.

The computed boundary layer thickness is plotted onto the observed ones in Fig. 7. The wind velocities are measured discontinuously in height, so that we obtain only discrete profiles of the wind velocity whose intervals of height in the middle region of the tunnels are $2 \mathrm{~cm}$. Therefore there are some uncertainties in the height and speed of the maximum wind due to discreteness of the data points. In Fig. 7, the observed heights are shown by the horizontal line segments each of which has the sign of vertical dash in the middle. This sign shows the height of the maximum wind velocity detected from the discrete data and the lefthand edge of each segment shows the height of the boundary layer $\delta$. where $\bar{u}(\delta)$ is equal to 99 percent of $u_{\infty}$ defined by the maximum wind velocity. The righthand side of the

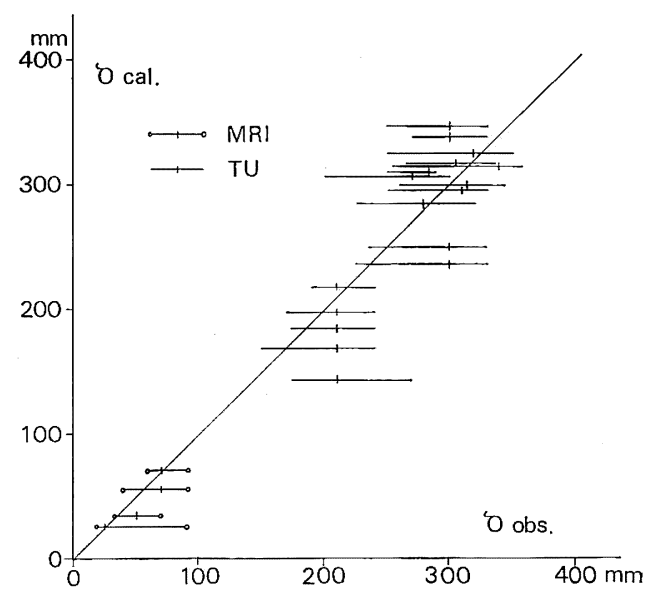

Fig. 7. Computational boundary layer thickness versus observed one. The width of horizontal line is the uncertainty of $\delta$. Vertical dash is the point of maximum wind velocity. Data, whose left edges of the horizontal lines touch the $\delta_{\text {obs }}=$ $\delta_{\text {cal }}$, seem to be reasonable. 
segment from the sign shows the area in which the maximum wind velocity may be actually attained but not detected due to the discrete measurements. Therefore the data whose segments meet the line $\delta_{\text {cal }}=\delta_{\text {obs }}$ at their lefthand side seem to be reasonable. It seems that the data whose $\delta_{\text {obs }}$ exceed 250 $\mathrm{mm}$ indicate that $\delta_{\text {obs }}$ may be less than $\delta_{\text {cal }}$. The height of the wind-wave tunnel in T. U. is $500 \mathrm{~mm}$, and so when the depth of the boundary layer exceeds half of the wind tunnel, these differences seem to appear. These experimental discrepancies may be due to the break of the boundary layer assumption of this method. Perhaps, after the boundary layer depth develops fully in the wind tunnel, turbulent mixing near the center of the tunnel is much stronger than that of the boundary layer edge, and we should use a slightly smaller coefficient in Hama's equation.

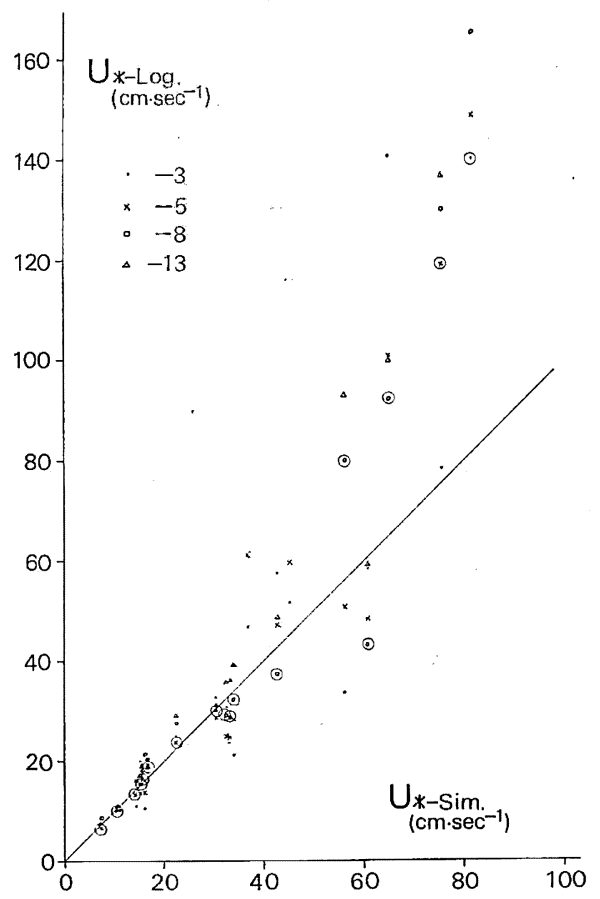

Fig. 8. Friction velocity due to the logarithmic profile method versus that due to the present method. Signs $8, \times, \bigcirc$ and $\triangle$ correspond to $u_{*}$-determination by using $3,5,8$ and 13 data points respectively, and large circles are the values using the lowest logarithmic part data by eyes.
Thus we may not be able to apply the method in this range.

A comparison between the calculated friction velocities by the logarithmic profile method and that by our method is shown in Fig. 8. Since we can not choose the proper parts of the velocity profile to apply the method from a physical consideration (see Fig. 1), the friction velocities are determined by least square fit to the log-law by use of the data at the 3rd, 5th, 8th and 13th points from the lowest point. Nearly 50 percent of discrepancies are seen in this figure due to the difference of the portion where the loglaw is applied. When $u_{*}$ is less than $40 \mathrm{~cm} /$ $\mathrm{sec}$, the friction velocity obtained by our procedure is nearly equal to that by the logarithmic one, while the latter exceeds the former when $u_{*}$ is greater than $40 \mathrm{~cm} / \mathrm{sec}$. This transition seems to occur in the range of $\delta$ greater than $250 \mathrm{~mm}$ in Fig. 7. Where the thickness of the boundary layer becomes greater than half of the wind tunnel height, it is likely that the whole flow in the tunnel becomes turbulent and we can not apply the boundary layer approximations as mentioned above.

As for the region where we should apply the logarithmic profile method, it seems reasonable to apply it to the lowest portion of the wind velocity profile, because we have only a small difference between the values obtained by the present method and the logprofile method. But we can not conclude about this until we have much more data.

If the wind profile is known, we can compute the distribution of the shear stress by use of Eq. (2.5). Fig. 9 shows some examples of them, when the external velocity does not vary with fetch. Non-dimensional stresses decrease monotonically towards the edge of the boundary layer, and no essential changes are found due to the variation of $\omega$. Although we use a log-profile for $\eta \leqq 0.15$ in our method, the shear stress does not seem to be constant in that layer. Consequently if there exists a constant-stress layer, we may expect a logarithmic profile, but even if we might find a logarithmic profile for 


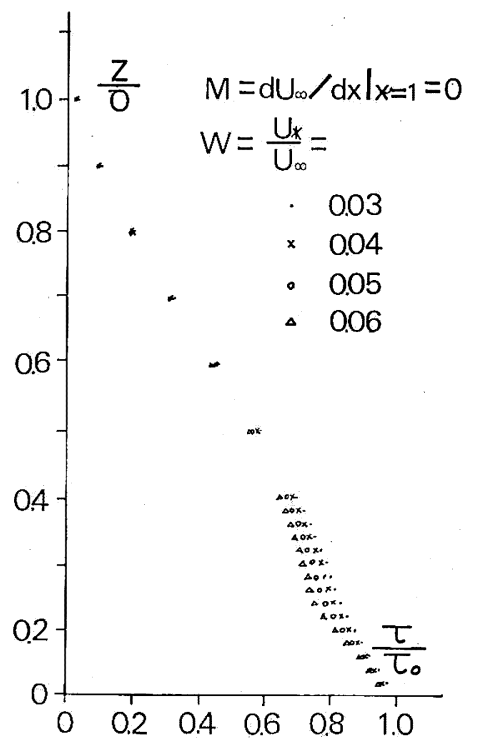

Fig. 9. Normalized shear stress profile for zero pressure gradient. $M$ is the rate of increment of the external flow. $W$ is the square of drag coefficient.

velocity distribution, we could not expect the existence of a constant-stress layer.

\section{Conclusions}

1. The velocity defect profile in the outer boundary layer in a wind-wave tunnel can be represented by Hama's equation, $F=9.6$ $(1-\eta)^{2}$, in the earlier stages when the boundary layer thickness does not exceed half of the wind tunnel height. The shear stress distribution as well as $u_{*}$ can be obtained using Hama's equation. The value of $u_{*}$ determined by this method is nearly equal to that by the logarithmic profile method in the above mentioned stages, but in the later stages when the thickness exceeds half of the tunnel height, the former method has a tendency to produce smaller values than the latter method.

2. The uncertainty of $u_{*}$ determined by the present method is within seven percent in our test. On the other hand the value of $u_{*}$ determined by the log-profile method may have discrepancies of several tens percent owing to the subjective selection of the layer to which the log-profile should be applied. Also the method can not be used especially when the logarithmic layer has not developed fully. When we use the log-profile method, application of a log-profile to the lower part of the velocity profile seems to yield similar friction velocities to that by our method.

3. Another merit of this method is its objectivity; the use of this method eliminates some uncertainties such as error due to the subjective selection of the layer to which a log-profile method should be applied.

4. Existence of a constant stress layer may yield the log-profile of a wind velocity theoretically and this is the physical background of the log-profile method. But even though the condition of constant-stress is not satisfied, we can encounter a log-profile in wind profile measurement because the other condition, for example the effect of energy diffusion, may compensate for the change of Reynolds stress as we see in the discussions of this paper. Therefore the experimental finding of a log-profile in a wind velocity distribution does not mean the existence of a constant-stress layer there.

Acknowledgement:-We would like to express our gratitude to Professor Y. Toba and the Wind-wave Studying Group in Tohoku University for providing data. We are also grateful to Dr. T. Nan-niti and Dr. I. Isozaki for helpful suggestions and a critical reading of the manuscript.

\section{References}

Chang, P.C., E.J. Plate and G. M. Hidy, 1971: Turbulent air flow over the dominant component of wind-generated water waves. J. Fluid Mech., 47, 183-208.

Charnock, H., 1955: Wind stress on a water surface. Quart. J. Roy. Met. Soc., 81, 639640.

Clauser, F. H., 1954: Turbulent boundary layer in adversed pressure gradients. J. Aero. Sci., 21, 91-108.

Kato, H. and K. Takemura, 1966: Wind profiles over the shallow water (1st Report). Rep. of Port and Harbour Res. Inst., 5, No. 1, 2-21. 
Kato, H. and K. Sano, 1971: An experimental study of the turbulent structure of wind over water waves. Rep. of Port and Harbour Res. Inst., 10, No. 1, 3-42.

Kawai, S., K. Okada and Y. Toba, 1977: Field data support of three-second power law and $g u_{*} \sigma^{-4}$-spectral form for growing wind waves. J. Oceanogr. Soc. Japan, 33, 137-150.

Kunishi, H., 1963: An experimental study on the generation and growth of wind waves (second paper). Special Contr. Geophys. Inst. Kyoto Univ., 1, 93-98.

Mitsuyasu, H., 1973: The one-dimensional wave spectra at limited fetch. Rep. Res. Inst. Appl. Mech., Kyushu Univ., 20, No. 66, 37-53.

Monin, A.S. and A. M. Yaglom, 1971: Statistical Fluid Mechanics. 1, 311-327, M. I. T. Press.

Nan-niti, T., A. Fujiki and H. Akamatsu, 1968: Micro-meteorological obsevations over the sea (1). J. Oceanogr. Soc. Japan, 24, 281-294.

Plate, E. J. and G. M. Hidy, 1967; Laboratory study of air flowing over a smooth surface onto small waves. J. Geophys. Res., 72, 46274641 .
Rotta, J.C., 1975: Turbulence. Translation to Japanese by M. Ohji, pp. 277, Iwanami-shoten.

Suzuki, Y., 1978: An experimental study of sensible and latent heat flux over water waves. M. Sc. thesis, Tohoku Univ., 1-62 (in Japanese).

Takeda, A., 1963: Wind profiles over sea waves. J. Oceanogr. Soc. Japan, 24, 281-294.

Toba, Y., 1972: Local balance in the air-sea boundary processes, 1 , on the growth process of wind waves. J. Oceanogr. Soc. Japan, 28, 109-120.

Toba, Y., 1976: Air sea boundary process. Physical Oceanography No. 1, pp. 184-195, Tokai Univ. Press (in Japanese).

Townsend, A.A., 1976: The Structure of Turbulent Shear Flow, second edition. pp. 259276, Cambridge Univ. Press.

Uji, T., 1978: Water waves induced by a fluctuating tangential stress. J. Oceanogr. Soc. Japan, $34,189-203$.

Uji, T., T. Konishi and K. Maruhashi, 1979: Test run report of the newly installed wind-wave tunnel. To be submitted by Umi to Sora (in Japanese).

\section{風洞水槽実験での摩擦速度の決定方法について}

$$
\text { 小西達男, 宇, 治豪 }
$$

乱流平衡境界厴の相似則を基礎に，風洞水槽実験で風波を記述する際の重要なパラメータである摩擦速度を決定 する方法を考党た。速度欠損則として，内部乱流境界層には対数プロフィルを，外部境界層には Hamaの式，F= $9.6(1-\eta)^{2}$ を用いる。ここで，F は無次元プロフィル関数，クは無次元高度である。この方法で決定される摩擦 速度誤差は数 \%と見込をれ，従来の対数プロフィルのみ加ら訃算する方法で沙不可避な直線の適用法による誤盖

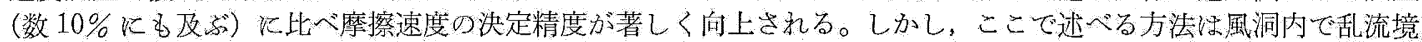

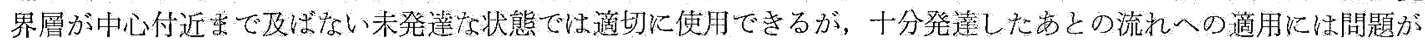
あるかもしれな。 